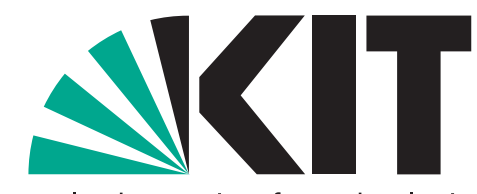

Karlsruher Institut für Technologie

\title{
Risk attitude, beliefs, and information in a corruption game - An experimental analysis
}

by Siegfried Berninghaus, Sven Haller, Tyll Krüger, Thomas Neumann, Stephan Schosser, Bodo Vogt

No. 6 | SEPTEMBER 2010

\section{WORKING PAPER SERIES IN ECONOMICS}

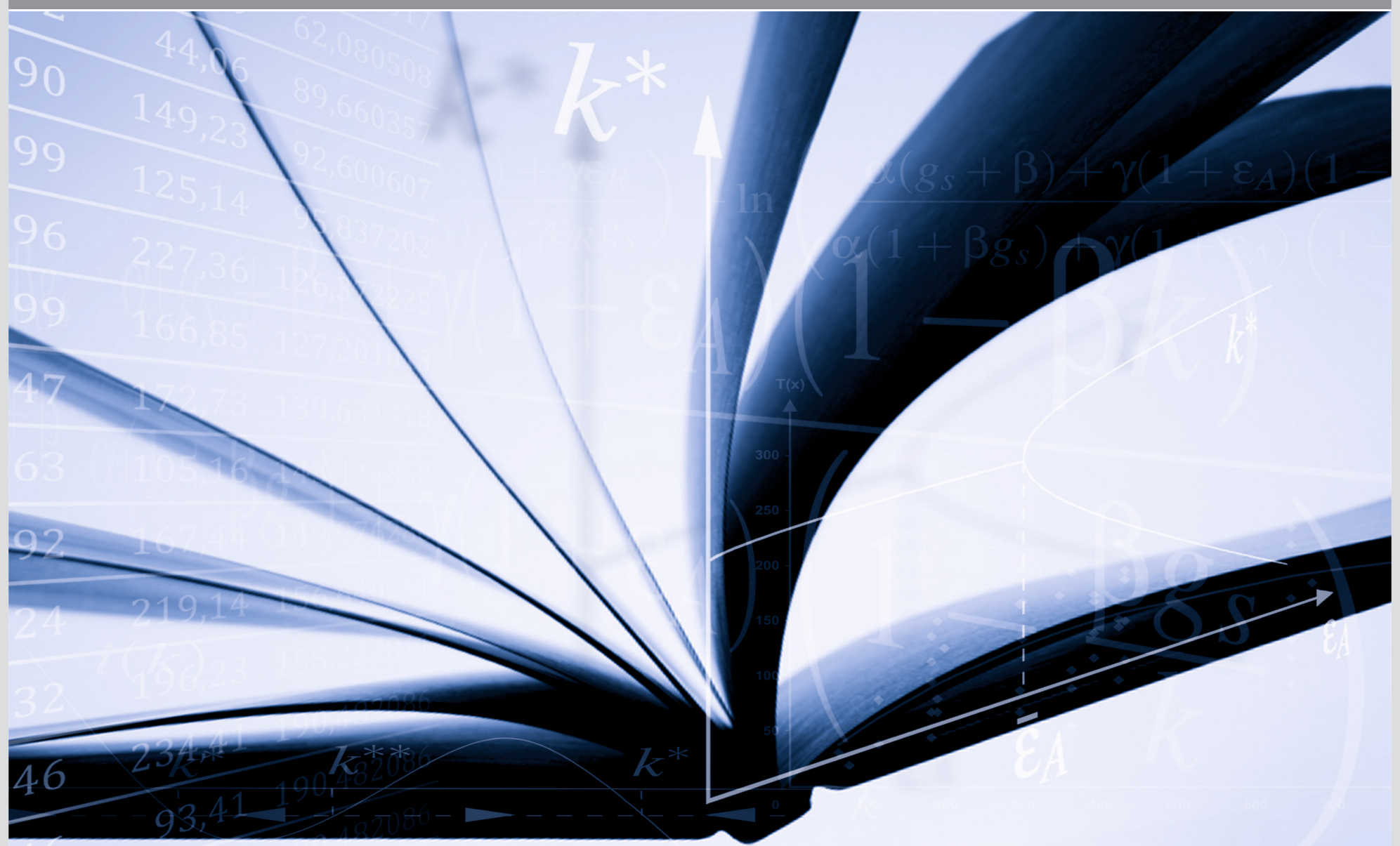




\section{Impressum}

Karlsruher Institut für Technologie (KIT)

Fakultät für Wirtschaftswissenschaften

Institut für Wirtschaftspolitik und Wirtschaftsforschung (IWW)

Institut für Wirtschaftstheorie und Statistik (ETS)

Schlossbezirk 12

76131 Karlsruhe

KIT - Universität des Landes Baden-Württemberg und nationales Forschungszentrum in der Helmholtz-Gemeinschaft

Working Paper Series in Economics

No. 6, September 2010 


\title{
Risk AtTITUde, BELIEFS, AND INFORMATION IN A CORRUPtion Game - An Experimental AnALYsIS ${ }^{1}$
}

\author{
Siegfried Berninghaus ${ }^{*}$, Sven Haller ${ }^{\#}$, Tyll Krüger ${ }^{+}$, Thomas Neumann", Stephan Schosser ${ }^{*}$, \\ Bodo Vogt ${ }^{\#}$ \\ ${ }^{*}$ Karlsruhe Institute of Technology (KIT), Institute for Economic Theory and Statistics, P.O. Box 6980, \\ D-76128 Karlsruhe, Germany, E-mail:vwl3office@ets.kit.edu \\ \# Otto-von-Guericke-University Magdeburg, Faculty of Economics and Management, P.O. Box 4120, \\ D-39016 Magdeburg, Germany, E-mail: bwl-ew@ovgu.de \\ + University of Bielefeld, Research Center BiBoS, P.O. Box 100131, D-33501 Bielefeld, Germany; \\ E-mail: tkrueger@physik.uni-bielefeld.de
}

\begin{abstract}
For our experiment on corruption we designed a coordination game to model the influence of risk attitudes, beliefs, and information on behavioral choices and determined the equilibria. We observed that the participants' risk attitudes failed to explain their choices between corrupt and non-corrupt behavior. Instead, beliefs appeared to be a better predictor of whether or not they would opt for the corrupt alternative. Furthermore, varying the quantity of information available to players (modeled by changing the degree of uncertainty) provided additional insight into the players' propensity to engage in corrupt behavior. The experimental results show that a higher degree of uncertainty in the informational setting reduces corruption.
\end{abstract}

\section{JEL-CLASSIFICATION: D73, K42, C91, C92}

KEYWORDS:

Corruption, game theory, experiment, risk attitude, beliefs

\footnotetext{
${ }^{1}$ We are grateful to Eike B. Kroll for his very helpful comments. In addition, we wish to thank Peter Martin as well as participants at the Economic Science Association - European Meeting 2009, the 7th Annual Conference of the German Law and Economics Association and the 4th French-German Talks in Law and Economics 2009 for their useful comments on how to sharpen the focus of the paper.

a Corresponding author: E-mail address: stephan.schosser@kit.edu, Phone: +49 721 608-6134, Fax: +49 721 608-3491
} 


\section{Introduction}

THE IMPORTANCE OF UNDERSTANDING CORRUPTION as an area of social behavior is widely accepted. Nearly all studies on institutional corruption show that the structures of governmental institutions and political processes are important determinants for the level of corruption (Shleifer and Vishny (1993)).

Various models have been designed to analyze different aspects of corruption (see e. g. Andvig and Moene (1990), Groenendijk (1997), Lui (1986), and Rose-Ackerman (1975)). Using the principal-agent-theory, the models provide insight into the relations between the participants in a corrupt act under different assumptions, such as asymmetric information and different kinds of costs. Andvig and Moene (1990) modeled corruption as a multiplayer coordination game in which public officials can choose between a corrupt or honest strategy. In this model, the number of other public officials choosing the same strategy affects each player's best response. For the briber, the expected profit of corrupt behavior depends on the number of dishonest public officials. The greater the number of dishonest public officials, the higher the payoff for the briber and the lower the probability of being caught in corrupt transactions will be.

In our study, we assumed a common situation of corruption in which several public officials were faced with the decision of whether or not to accept bribes. Guided by the theoretical explanations of Andvig and Moene (1990), we configured this situation as a coordination game in which the acceptance of bribes led to a higher payoff connected with the risk of being caught. To represent this risk, we introduced a government agency charged with uncovering corrupt public officials. However, due to the agency's assumed budget constraints, the number of corrupt public officials is inversely proportional to their individual probabilities of being caught. In other words, the more corrupt officials there are, the lower the chance of detection and vice versa. In this kind of scenario, it might be rational for a profit-maximizing public official or utility-maximizing agent to act corruptly (Tirole (1996)).

A lack of information about probabilities is commonly referred to as "uncertainty" (Knight (1921)). The literature on the economics of uncertainty explains the relevance of uncertainty for economic behavior (Lippman et al. (1981)). Cadot (1987), for example, has shown that risk is a parameter of the decision to engage in corrupt acts; accordingly, we elicited the risk attitudes of the players in our experiment by using lottery choices. Then, assuming fixed government anti-corruption expenditures, we modeled risk as a dynamic parameter depending on the overall number of players choosing the same strategy, thereby introducing elements of strategic uncertainty. Having set this groundwork, we studied the relationship between risk and uncertainty by comparing the players' lottery choices with their strategic behavior in the coordination game. Neumann and Vogt (2009) have demonstrated that the players' beliefs seem to be a better predictor of their decisions in a coordination game than risk attitude alone. Therefore, we elicited our players' beliefs and analyzed whether they accurately predicted their behavior in the corruption game.

Increasing information about corruption has been shown to greatly reduce corrupt behavior (Reinikka and Svensson (2004)). In our experiment, we chose not to simply increase information about corruption but to vary the amount of information about the probability of individual corrupt behavior being uncovered, which refers to varying the degree of uncertainty.

Our analyses show that the players' decisions were not determined by their risk attitudes, meaning that a more risk-seeking player did not necessarily behave more corruptly. On the contrary, the 
elicited beliefs proved to be much better predictors of behavior. With respect to corruption, our players built subjective probabilities about the possibility of successfully accepting a bribe. Furthermore, we found that increasing uncertainty among the players by informing them that corrupt acts had been uncovered by the government agency served to reduce corruption. For that purpose, it was not necessary to provide information about the specific activities undertaken by the agency, but merely to convey the risk of getting caught.

In the next section we present our game design, theoretical predictions, and research hypotheses. Section 3 explains our experimental design and in Section 4 we describe our results. Finally, Section 5 concludes the paper by discussing some strategic recommendations to reduce corruption.

\section{Game Design}

In the literature, games with multiple equilibria, especially coordination games, are often used to model corruption (e.g. Cadot (1987) and Andvig and Moene (1990)). Coordination games are typical examples of uncertain situations representing the tradeoff between uncertainty and the resulting outcome. In an attempt to resolve this tradeoff, Harsanyi and Selten (1988) introduced two selection criteria: risk dominance and payoff dominance. There appears to be no common consensus in the literature on which factor determines equilibrium selection in coordination games. Nevertheless, besides the payoff structure, three aspects are central to this discussion: (1) beliefs, (2) risk, and (3) uncertainty. Since it is well known that the equilibrium selection in coordination games requires knowledge about the other players' behavior, it is logical to assume that the players' beliefs might influence the outcome. In addition, uncertainty might influence behavior. In this case, two different kinds of uncertainty are involved (Knight (1921)): 1) exogenous uncertainty (risk) with given and known a priori probabilities for all possible states of the world and 2) endogenous uncertainty, which arises from the lack of such probabilities. In the remainder of this paper, uncertainty is meant to be understood as endogenous uncertainty.

To investigate the impact of risk on corruption, we used lottery choices to elicit the risk attitude of the players. We compared these results to a coordination game in which the players faced decisions between a sure payoff (riskless option) if they behaved honestly and a risky option if they engaged in corrupt behavior. We modeled the risky option as a binary lottery. The probability of receiving the higher payoff was a function of the overall number of players who decided to play the lottery. The sure payoff (riskless option) was referred to as the "salary per month". In the risky option, the higher payoff consisted of the salary per month plus a bribe amount.

We analyzed the impact of uncertainty by playing two versions of the coordination game with different degrees of uncertainty: (1) a Corruption Game and (2) a Modified Corruption Game. During the Corruption Game all players knew the functional relation of the number of players playing the lottery and the probability of receiving the higher payoff. The players did not know which lottery would be realized, but were aware of the probabilities for all possible lotteries. In the Modified Corruption Game, we increased the degree of uncertainty. In this case, we did not inform the players about the probabilities; we only told them that the probability of winning the risky option would increase with the number of players choosing this option.

Finally, we elicited the players' beliefs by means of direct belief elicitation in the Modified Corruption Game. 


\subsection{Lottery choices - elicitation of risk attitudes}

To analyze the influence of players' risk attitudes on decisions in a game, we had to identify their specific risk attitudes. For this purpose, we asked the players to choose between two alternatives, i.e. Alternative A, a secure payoff, and Alternative B, a lottery, in 13 different runs. Table 1 shows the fixed payoff and probabilities for each of the 13 lottery runs. Alternative $A$ shows the fixed payoff of 600 points. The first column of Alternative B shows the probabilities $(1-w)$ of obtaining 0 points, and the second column of Alternative B indicates the probabilities $(w)$ of obtaining 1,000 points.

\begin{tabular}{|c|c|c|c|}
\hline No. & $\begin{array}{c}\text { Alternative A } \\
\text { (secure payoff) }\end{array}$ & \multicolumn{2}{|c|}{$\begin{array}{c}\text { Alternative B } \\
{[0,(1-w) ; 1,000, w]}\end{array}$} \\
\hline 1 & 600 Points & .99 & .01 \\
\hline 2 & 600 Points & .95 & .05 \\
\hline 3 & 600 Points & .90 & .10 \\
\hline 4 & 600 Points & .80 & .20 \\
\hline 5 & 600 Points & .70 & .30 \\
\hline 6 & 600 Points & .60 & .40 \\
\hline 7 & 600 Points & .50 & .50 \\
\hline 8 & 600 Points & .40 & .60 \\
\hline 9 & 600 Points & .30 & .70 \\
\hline 10 & 600 Points & .20 & .80 \\
\hline 11 & 600 Points & .10 & .90 \\
\hline 12 & 600 Points & .05 & .95 \\
\hline 13 & 600 Points & .01 & .99 \\
\hline
\end{tabular}

Table 1: Eliciting players' risk attitudes

We used this design to identify the point at which the players switched from the (sure) Alternative A to the (risky) Alternative B. This "multiple pricing list" design for measuring risk aversion was inspired by Holt and Laury (2002).

According to the findings of Heinemann et al. (2004), participants use threshold strategies, meaning that they should choose Alternative A for low probabilities of obtaining the high payoff in the risky option and switch to Alternative $B$ only once and stay with Alternative $B$ for the remaining runs. A risk-neutral agent, for example, would switch from Alternative A to Alternative B between Nos. 8 and 9 of Table 1. The later an agent switches from $A$ to $B$ the higher the degree of an agent's risk aversion. Playing a threshold strategy corresponds to the agent's risk attitude, meaning that players who use a threshold strategy have an explicit switching point. This switching point served as our indicator for the players' risk attitudes.

\subsection{Corruption Game}

Inspired by Andvig and Moene's (1990) model of corruption, we designed our game according to a common situation of corruption in which several public officials face a decision of whether to accept bribes (and thus receive an increased payoff), or to abstain from taking bribes and merely live on their "regular salary". This scenario includes a government agency that fights corruption by attempting to catch corrupt officials. The number of officials participating in our corruption game was $N=6$. We assumed that the probability $w(m)$ of not being detected depended monotonically increasing the number $m$ of officials accepting bribes $(N \geqq m \geqq 1)$. 


$$
w(m)=\left\{\begin{array}{l}
.5 \text { if } m=1 \\
.6 \text { if } m=2 \\
.7 \text { if } m=3 \\
.8 \text { if } m=4 \\
.9 \text { if } m=5 \\
1 \text { if } m=6
\end{array}\right.
$$

The monotonicity property of $w(\cdot)$ seems to be plausible and is also consistent with the literature on corruption. We modeled our corruption game as a non-cooperative game $G=\left(\sum_{1}, \ldots, \sum_{N} ; H_{1}(\cdot), \ldots, H_{N}(\cdot)\right)$ with $N$ players, where the strategy sets are defined by

$$
\sum_{1}=\cdots=\sum_{N}=\{A, B\} .
$$

$A$ denotes the strategy "refusing bribes" and $B$ denotes the strategy "accepting bribes".

Strategy $A$ generates a fixed and certain payoff of 600 points (the "monthly salary") independently of the strategy choice of the remaining players. Strategy $B$ yields the expected value ${ }^{2}$ of a lottery $\mathcal{L}=\{0,(1-w(m)) ; 1,000, w(m)\}$, where 1,000 is the total monthly salary $(=600)$ plus the amount of the bribes $(=400)$ offered to an official that will be consumed with probability $w(m)$. If convicted (with probability $1-w(m)$ ), the official has to return both the bribery money and his salary. In other words, the payoff functions $H_{i}: \sum_{1} \times \ldots \times \sum_{N} \rightarrow \mathbb{R}$ are characterized as follows ${ }^{3}$ :

$$
\begin{gathered}
H_{i}\left(\cdot, \sigma_{i}\right)=600 \text { for } \sigma_{i}=A \\
H_{i}\left(\sigma_{-i}, \sigma_{i}\right)=w(m) 1,000 \text { for } \sigma_{i}=B \\
\text { and } m:=\left|\left\{j \in I \mid j \neq i, \sigma_{j}=B\right\}\right| .
\end{gathered}
$$

One can easily show that there exist only two Nash equilibria in pure strategies.

\section{Result 1: $\quad$ The Nash equilibria in pure strategies of the corruption game $G$ are given by}

$$
\begin{aligned}
\boldsymbol{\sigma}^{*} & =\left(\boldsymbol{\sigma}_{1}^{*}, \ldots, \boldsymbol{\sigma}_{N}^{*}\right)=(\boldsymbol{A}, \ldots, \boldsymbol{A}), \\
\boldsymbol{\sigma}^{* *} & =\left(\boldsymbol{\sigma}_{1}^{* *}, \ldots, \boldsymbol{\sigma}_{N}^{* *}\right)=(\boldsymbol{B}, \ldots, \boldsymbol{B}) .
\end{aligned}
$$

Sketch of a proof: Suppose that all officials choose $A$, which results in a payoff equal to 600; then unilateral deviation to $B$ would result in a payoff of $500(=w(1) \cdot 1,000)$.

Suppose that all officials choose $B$, which results in an individual payoff of 1,000 . Unilateral deviation to $A$ reduces the individual payoff to 600 .

Consider any strategy configuration $\sigma \neq \sigma^{*}, \sigma^{* *}$. Let $\sigma$ be characterized by $m=1$. The unique B-player has a payoff of 500 , but she can improve her payoff by switching to $A$. In the situation where the number of officials choosing $B$ satisfies $1<m<N$, all $B$-players obtain $w(m) \cdot 1,000$. Then at least one $A$-player would earn $w(m+1) 1,000>w(m) 1,000 \geqq 600$. There is no other Nash equilibrium in pure strategies for game $G$.

\footnotetext{
${ }^{2}$ We assume risk-neutral decision-makers.

${ }^{3}$ Note that we use the well-known convention to abbreviate the strategy configuration $\left(\sigma_{1}, \ldots, \sigma_{i-1}, \sigma_{i+1}, \ldots, \sigma_{N}\right)$ by $\sigma_{-i}$.
} 
Moreover, there is a symmetric strictly mixed equilibrium $s^{*}=\left(\left(q_{A}, 1-q_{A}\right), \ldots,\left(q_{a}, 1-q_{A}\right)\right)$, where $q_{A}$ denotes the probability of choosing strategy $A$.

\section{Result 2: $\quad$ There exists a symmetric strictly mixed equilibrium with $q_{A}=0.2$.}

Proof: We have to show that each official is indifferent between $A$ and $B$ when all remaining players choose $q_{A}$, i.e.

$$
\forall i: H_{i}\left(s_{-i}^{*}, A\right)=H_{i}\left(s_{-i}^{*}, B\right),
$$

which is equivalent to $H_{i}\left(s_{-i}^{*}, B\right)=600$.

Note that $H_{i}\left(s_{-i}^{*}, B\right)$ can be written as $\sum_{k=0}^{5} p_{k} w(k) 1,000$, where $p_{k}$ denotes the probability that exactly $k$ of the other officials choose $B$ when all execute the same mixed strategy $s_{i}^{*}=\left(q_{A}, 1-q_{A}\right)$. Since officials make their decisions independently of each other, we can calculate $p_{k}$ via binomial distribution

$$
p_{k}=\left(\begin{array}{l}
N \\
k
\end{array}\right)\left(1-q_{A}\right)^{k} q_{A}^{N-k}
$$

For $q_{A}=0.2$ we obtain

$$
p=\left(p_{0}, \ldots, p_{5}\right)=(0.3277,0.4096,0.2048,0.0512,0.0064,0.0003),
$$

which results in $\sum_{k=0}^{5} p_{k} w(k) 1,000=600$.

q.e.d.

\subsection{Modified Corruption Game - direct belief elicitation}

The Modified Corruption Game is a variation of the Corruption Game explained in Section 2.2. We varied the degree of uncertainty in this case by providing less information about the functional relation of the number of players choosing the risky alternative and the probability of receiving the higher payoff in this risky alternative. In this version the players only knew that the probability of obtaining the higher payoff in the risky alternative would increase with the number of players choosing this alternative.

We felt that eliciting the players' beliefs might help shed light on their decision-making processes. The literature basically provides two different elicitation procedures: direct or indirect. ${ }^{4}$ In the Modified Corruption Game, we elicited the players' beliefs directly by asking them to estimate the probability of Alternative B leading to the higher payoff in every decision run. Following Nyarko and Schotter (2002), we rewarded the players according to a quadratic scoring rule that conforms to the axiomatic characterization as formulated by Selten (1998).

The rewarding function was designed as follows:

$E=150 \cdot\left[1-\left(w(m)-\frac{b}{100}\right)^{2}\right] \quad \begin{aligned} & \text { with } \mathrm{w}(\mathrm{m})=\text { real probability of obtaining the higher } \\ & \text { payoff, and } \mathrm{b}=\text { players' first-order belief }\end{aligned}$

\footnotetext{
${ }^{4}$ For an overview on measuring expectations, see Manski (2004).
} 
We asked the players to express their estimates as a number between 0 (Alternative $B$ provides 0 points for sure) and 100 (Alternative B provides 1,000 points for sure). We designed this function such that it is optimal for a risk-neutral agent to report her true belief (see e. g. Nyarko and Schotter (2002) and Gerber (2006)). Due to different risk attitudes or probability weighting, players frequently misreport their true beliefs (Sonnemans and Offerman, 2001).

\section{Research Hypotheses}

The relation between risk and behavior in games has been examined in many studies (see e.g. Straub (1995), Schmidt et al. (2003), or Goeree et al. (2003)). Experiments show that players' risk attitudes often influence their behavior in games. According to Cadot (1987), corruption (or crime) is a lottery, and players who ask for (or offer) bribes face risks every time. Hence, we can conclude that players' risk attitudes determine their decisions in these kinds of situations. Our first hypothesis is therefore:

H1: $\quad$ The players' risk attitudes determine their decisions in the game.

In the context of the described game, this implies that risk-loving players should favor the risky alternative.

In coordination games such as ours, equilibrium behavior requires knowledge about the other players' behavior. In addition to analyzing the players' risk attitudes, we also investigated the influence of their beliefs on their behavior. Players' beliefs have been elicited in several studies (see e.g. Nyarko and Schotter (2002), Costa-Gomes and Weizsäcker (2008), or Palfrey and Wang (2009)). All of the studies show that beliefs concerning the behavior of others influence the outcome of a game. In keeping with this finding, our corresponding hypothesis is:

H2: $\quad$ The players' beliefs determine their decisions in the game.

In the game, we investigated the influence of the players' first-order beliefs and related these beliefs to their risk attitudes. Thus, we were not only interested in the determining influences; we also studied whether the players' behavior was consistent with respect to their risk attitudes and beliefs.

In economic theory, corruption can be modeled as a game and solved under different assumptions of information sets (Cadot (1987)). Different studies have pointed out that information can be a powerful tool for reducing corruption (see e. g. Reinikka and Svensson (2004), Brunetti and Weder (2003), and Cadot (1987)). In the game we used, different degrees of uncertainty corresponded to different information sets. Hence, we will analyze the following hypothesis:

H3: $\quad$ The degree of uncertainty does not affect players' decisions.

In our study we varied the degree of uncertainty by providing different information about the probability of obtaining the higher payoff in the risky (corrupt) alternative. By analyzing the fraction of players choosing the risky alternative in the different setups, we were able to determine the influence of the varied information sets. 


\section{The Experiment}

Following the description given in Section 2, we ran a neutrally framed experiment. Given that Abbink and Henning-Schmidt (2006) found no significant differences in a bribery experiment run in both a loaded and unloaded frame, we used an unloaded frame to avoid framing effects.

We conducted two treatments: (1) the Baseline Treatment, consisting of the Corruption Game and lottery choices, and (2) the Uncertain Treatment, consisting of the Modified Corruption Game and lottery choices.

The experiment was performed in the MaXLab, the experimental laboratory at the University of Magdeburg in September 2008. We ran six sessions for each treatment, with six participants in each session. The participants were recruited using ORSEE software (Greiner (2004)) from a pool consisting mostly of students from various faculties. For our computerized experiment, we used a program written in z-tree (Fischbacher (2007)). The participants received separate instructions for each part of the experiment. All instructions were provided in German. An English translation of the written instructions is shown in Appendix C.

No communication was allowed among the participants at any time during the experiment. In the Baseline Treatment, participants could earn a maximum of 7.33 euros and in the Uncertain Treatment a maximum of 8.33 euros. The experiment provided a riskless payoff of 4.40 euros in the Baseline Treatment and of 5.15 euros in the Uncertain Treatment. The payoffs in the experiment were given in points and were converted into euros at the end of the experiment. The exchange rate we used was 1 euro cent for every 15 points.

\subsection{Lottery choices - elicitation of risk attitudes}

To elicit the players' risk attitudes, we commenced both treatments, i.e. the Baseline Treatment and the Uncertain Treatment, with the lottery choices.

In this part, for 13 lotteries, participants were asked to compare these lotteries with a riskless payoff of 600 points. The lotteries $\left[G_{1},(1-w) ; G_{2}, w\right]$ provided a payoff $\left[G_{1}\right]$ of 0 points with probability $[(1-w)]$ and with probability $[w]$ a payoff $\left[G_{2}\right]$ of 1,000 points. For these 13 runs, the participants had to decide between the lottery, the sure payoff or an indifferent position.

At the end of the experiment, one of the 13 decision scenarios was randomly chosen and actualized. The particular scenario was determined by drawing a ball from a bingo cage containing 13 balls numbered from 1 to 13. For each participant, his or her preferred alternative was realized (i.e. either the lottery or the sure payoff). In the case of the lottery, a ball was drawn from a bingo cage containing a specified number of red and blue balls corresponding to the probabilities of the determined lottery (the number of red balls reflected the probability $[(1-w)]$ of payoff $\left[G_{1}\right]$ and the number of blue balls reflected the probability $[w]$ of the payoff $\left.\left[G_{2}\right]\right)$. In the case of indifference, a coin toss determined which alternative was realized.

\subsection{Corruption Game}

In the Baseline Treatment, we played the Corruption Game after the lottery choice. In this game, the participants were informed that they would be playing in a group of six participants. Each player was presented with two different alternatives: Alternative $A$, carrying a certain payoff of 600 points, and Alternative $\mathrm{B}$, carrying a risky payoff of 1,000 points with probability $[w(m)]$ or 0 points with probability $[1-w(m)]$ depending on the number of participants choosing Alternative B. Subjects 
were shown a table containing the resulting probability outcomes according to the number of participants choosing Alternative B.

The participants were asked to choose one of the alternatives or to indicate indifference between the two. In the case of indifference, one alternative was randomly selected (with a probability of 0.5 for each alternative). This part was repeated 10 times.

Losing the lottery was equivalent to being convicted of bribery by the government agency. In our game, the way in which the agency went about uncovering corruption was irrelevant; the important aspect was that the participants knew there was a possibility of being caught. Therefore, after each period, we informed all participants about the number of convicted players.

\subsection{Modified Corruption Game}

In the Uncertain Treatment, the lottery choice was followed by the Modified Corruption Game, in which the probabilities of receiving the higher payoff in the risky alternative (B) were unknown to the players. The players only knew that the probabilities $[w(m)]$ would increase along with the number of participants who chose Alternative B.

Additionally, the players were asked to estimate the probability of obtaining the higher payoff from Alternative $B(1,000$ points) on a scale from 0 to 100 . Players were then rewarded according to a quadratic scoring function as explained in Section 2. This part was repeated 10 times.

\section{Results}

In the remainder of the paper, we will first analyze the lottery choices in order to relate the players' risk attitudes to their observed behavior in our Corruption Game as well as to that observed in our Modified Corruption Game. Afterwards, we will examine the players' expectations about each other's behavior.

\subsection{Descriptive statistics: lottery choices - elicitation of risk attitudes}

In the lottery choices, the participants had to decide between a sure payoff (Alternative A) and a risky payoff (Alternative B). In line with the findings of Heinemann et al. (2004) and Heinemann et al. (2009), the majority of the participants in our study (64 out of $72 \approx 89 \%$ ) chose a threshold strategy. The switching point of the threshold strategy is given by the probability of obtaining the higher payoff in Alternative B for the lottery number at which point the players switched from Alternative $A$ to Alternative B. In Table 2, we present the switching points of the 64 players who utilized a threshold strategy. 


\begin{tabular}{|c|c|c|c|c|c|}
\hline No. & Alternative A & \multicolumn{2}{|c|}{$\begin{array}{c}\text { Alternative B } \\
{[0,(1-w) ; 1,000, w]}\end{array}$} & $\begin{array}{c}\text { No. of players who } \\
\text { switched from } \\
\text { Alternative A to } \\
\text { Alternative B }\end{array}$ & $\begin{array}{c}\text { No. of players who } \\
\text { switched from } \\
\text { Alternative B to } \\
\text { Alternative A }\end{array}$ \\
\hline 1 & 600 Points & .99 & .01 & 0 & 0 \\
\hline 2 & 600 Points & .95 & .05 & 0 & 0 \\
\hline 3 & 600 Points & .90 & .10 & 0 & 0 \\
\hline 4 & 600 Points & .80 & .20 & 0 & 0 \\
\hline 5 & 600 Points & .70 & .30 & 1 & 0 \\
\hline 6 & 600 Points & .60 & .40 & 1 & 0 \\
\hline 7 & 600 Points & .50 & .50 & 13 & 0 \\
\hline 8 & 600 Points & .40 & .60 & 13 & 0 \\
\hline 9 & 600 Points & .30 & .70 & 20 & 0 \\
\hline 10 & 600 Points & .20 & .80 & 8 & 0 \\
\hline 11 & 600 Points & .10 & .90 & 6 & 0 \\
\hline 12 & 600 Points & .05 & .95 & 2 & 0 \\
\hline 13 & 600 Points & .01 & .99 & 0 & 0 \\
\hline
\end{tabular}

Table 2: Switching points of the 64 players who employed a threshold strategy

For the other 8 players, we were not able to identify a "clear" strategy. These players' decisions and their switches within the 13 lottery choices are shown in Appendix B.3.

The lottery choices and the switching points for all participants are presented in Table 3. In Decision No. 8, the expected payoff of Alternative B was equal to the sure payoff of Alternative A. Thus, a riskneutral player would have been indifferent between the two alternatives. Switching earlier represents risk-seeking behavior and switching later reflects risk aversion.

One can see, all participants showed similar risk attitudes. In Decisions Nos. 1 to 7, the majority of players chose Alternative A, in Decisions Nos. 11 to 13, the majority chose Alternative B. That means, within the range of Decisions Nos. 8 to 10 , the majority of players switched from Alternative $A$ to $B$. Thus, we conclude that the majority of players in our study were risk averse. Appendix B contains separate tables for each treatment. In Table 3, we present the risk attitudes of the participants by their given switching points. 


\begin{tabular}{|c|c|c|c|c|c|c|}
\hline No. & Alternative A & \multicolumn{2}{|c|}{$\begin{array}{c}\text { Alternative B } \\
{[0,(1-w) ; 1,000, w]}\end{array}$} & $\begin{array}{c}\text { No. of } \\
\text { players who } \\
\text { chose A }\end{array}$ & $\begin{array}{c}\text { No. of players } \\
\text { who chose B }\end{array}$ & $\begin{array}{c}\text { No. of } \\
\text { indifferent } \\
\text { players }\end{array}$ \\
\hline 1 & 600 Points & .99 & .01 & 63 & 5 & 4 \\
\hline 2 & 600 Points & .95 & .05 & 67 & 3 & 2 \\
\hline 3 & 600 Points & .90 & .10 & 68 & 3 & 1 \\
\hline 4 & 600 Points & .80 & .20 & 70 & 1 & 1 \\
\hline 5 & 600 Points & .70 & .30 & 68 & 2 & 2 \\
\hline 6 & 600 Points & .60 & .40 & 68 & 4 & 0 \\
\hline 7 & 600 Points & .50 & .50 & 52 & 12 & 8 \\
\hline 8 & 600 Points & .40 & .60 & 42 & 12 & 18 \\
\hline 9 & 600 Points & .30 & .70 & 18 & 42 & 12 \\
\hline 10 & 600 Points & .20 & .80 & 9 & 55 & 8 \\
\hline 11 & 600 Points & .10 & .90 & 3 & 68 & 1 \\
\hline 12 & 600 Points & .05 & .95 & 1 & 70 & 1 \\
\hline 13 & 600 Points & .01 & .99 & 0 & 72 & 0 \\
\hline
\end{tabular}

Table 3: Chosen alternative and switching point

\subsection{Descriptive statistics: Corruption Game}

In the Corruption Game, players were asked to decide between two alternatives: Alternative $A$, which led to a sure payoff, and Alternative $B$, which led to an uncertain payoff.

As described in Section 2.2, Alternative B in the Corruption Game was reflected by a lottery. The probability $w(m)$ of not being detected (obtaining the higher payoff) depended on the number $m$ of subjects choosing Alternative B. Therefore, the participants knew of all 6 possible occurrences of the lotteries but were uncertain about which one reflected Alternative B. Table 4 represents the players' decisions. As the table shows, in each period, the majority of players chose Alternative $B$.

\begin{tabular}{|c|c|c|c|}
\hline $\begin{array}{c}\text { Period } \\
\text { No. }\end{array}$ & $\begin{array}{c}\text { No. of players } \\
\text { who chose A }\end{array}$ & $\begin{array}{c}\text { No. of players } \\
\text { who chose B }\end{array}$ & $\begin{array}{c}\text { No. of indifferent } \\
\text { players }\end{array}$ \\
\hline 1 & 9 & 27 & 0 \\
\hline 2 & 10 & 26 & 0 \\
\hline 3 & 5 & 31 & 0 \\
\hline 4 & 7 & 29 & 0 \\
\hline 5 & 8 & 28 & 0 \\
\hline 6 & 4 & 32 & 0 \\
\hline 7 & 5 & 31 & 0 \\
\hline 8 & 8 & 28 & 0 \\
\hline 9 & 4 & 32 & 0 \\
\hline 10 & 8 & 28 & 0 \\
\hline
\end{tabular}

Table 4: Chosen alternative in the Corruption Game 


\subsection{Descriptive statistics: Modified Corruption Game}

In this part, we modified our Corruption Game as explained in Section 2.2. Table 5 shows the players' decisions.

\begin{tabular}{|c|c|c|c|}
\hline Period No. & $\begin{array}{c}\text { No. of players } \\
\text { who chose A }\end{array}$ & $\begin{array}{c}\text { No. of players } \\
\text { who chose B }\end{array}$ & $\begin{array}{c}\text { No. of } \\
\text { indifferent } \\
\text { players }\end{array}$ \\
\hline 1 & 14 & 22 & 0 \\
\hline 2 & 12 & 24 & 0 \\
\hline 3 & 18 & 18 & 0 \\
\hline 4 & 16 & 20 & 0 \\
\hline 5 & 16 & 20 & 0 \\
\hline 6 & 12 & 24 & 0 \\
\hline 7 & 14 & 22 & 0 \\
\hline 8 & 16 & 20 & 0 \\
\hline 9 & 14 & 22 & 0 \\
\hline 10 & 18 & 17 & 1 \\
\hline
\end{tabular}

Table 5: Chosen alternative in the Modified Corruption Game

In addition, in each of the 10 rounds, we asked the players to estimate the probability of obtaining the higher payoff. Table 6 shows the players' beliefs (as probabilities) sorted according to their chosen alternative.

\begin{tabular}{|c|c|c|}
\hline Period No. & $\begin{array}{c}\text { Means of the beliefs of } \\
\text { players who chose A }\end{array}$ & $\begin{array}{c}\text { Means of the beliefs of } \\
\text { players who chose B }\end{array}$ \\
\hline 1 & .28 & .67 \\
\hline 2 & .28 & .71 \\
\hline 3 & .25 & .75 \\
\hline 4 & .21 & .71 \\
\hline 5 & .26 & .67 \\
\hline 6 & .15 & .73 \\
\hline 7 & .17 & .69 \\
\hline 8 & .31 & .76 \\
\hline 9 & .26 & .76 \\
\hline 10 & .25 & .84 \\
\hline $\begin{array}{c}\text { Mean of all } \\
\text { rounds }\end{array}$ & .24 & .72 \\
\hline
\end{tabular}

Table 6: Means of the elicited beliefs of obtaining the higher payoff (Modified Corruption Game)

\subsection{Research hypotheses}

To test our hypotheses on whether risk attitudes or beliefs (Hypotheses 1 and 2) determine the players' decisions, we grouped the players' decisions according to the alternative they had chosen in the games, i.e. Alternative $A$ and Alternative $B$, for both treatments separately.

Baseline Treatment. For this treatment, we compare the means of the switching points in the lottery choices. Table 7 shows the switching points of the players in the Baseline Treatment, grouped by 
their decisions in the Corruption Game. We reported the decisions of only 30 players (=300 decisions) because 6 players in the Baseline Treatment did not play a threshold strategy. As one can see, the switching points did not differ significantly between the two groups in this treatment. In other words, we found no correlation (coefficient of correlation $=0.0286$ ) between the switching points in the lottery choices and the decisions of the players in the Corruption Game.

However, we also failed to find any significant evidence that the players' risk attitudes determined their choices in the game, and thus we reject our first hypothesis.

\begin{tabular}{|l|c|c|}
\hline & $\begin{array}{c}\text { No. of decisions in the } \\
\text { Corruption Game }\end{array}$ & $\begin{array}{c}\text { Means of switching points in the } \\
\text { lottery choices (Baseline Treatment) }\end{array}$ \\
\hline $\begin{array}{l}\text { Alternative A } \\
\text { (sure payoff) }\end{array}$ & 49 & .67 \\
\hline $\begin{array}{l}\text { Alternative B } \\
\text { (risky payoff) }\end{array}$ & 251 & .69 \\
\hline
\end{tabular}

Table 7: Switching points and chosen alternative (Baseline Treatment)

Uncertain Treatment. According to the analysis of the Baseline Treatment above, we reported the decisions of 34 players ( $=340$ decisions) in the Modified Corruption Game. In Table 8, we show only 339 decisions because one player was indifferent in the last of the 10 rounds. In this treatment, two players did not play a threshold strategy.

As shown in Table 8, the beliefs of players choosing Alternative A in the Modified Corruption Game were significantly lower than in the other group (Mann-Whitney $U$ Test, $<1 \%$-level). The switching points were not significantly different, and as in the Baseline Treatment, we found no correlation (coefficient of correlation $=-0.1672$ ) between the switching points and the decisions. In contrast, the players' beliefs were highly correlated with their decisions (coefficient of correlation $=0.6448$ ). We can therefore conclude that the players' beliefs determined their choices in the game, and thus affirm our second hypothesis.

\begin{tabular}{|l|c|c|c|}
\hline & $\begin{array}{c}\text { No. of decisions } \\
\text { in the Modified } \\
\text { Corruption Game }\end{array}$ & $\begin{array}{c}\text { Means of the switching } \\
\text { points in the lottery choices } \\
\text { (Uncertain Treatment) }\end{array}$ & $\begin{array}{c}\text { Means of the beliefs (of } \\
\text { obtaining the higher payoff) in } \\
\text { the Modified Corruption Game }\end{array}$ \\
\hline $\begin{array}{l}\text { Alternative A } \\
\text { (sure payoff) }\end{array}$ & 144 & .68 & .24 \\
\hline $\begin{array}{l}\text { Alternative B } \\
\text { (risky payoff) }\end{array}$ & 195 & .63 & .72 \\
\hline
\end{tabular}

Table 8: Switching point and chosen alternative (Uncertain Treatment)

Upon analyzing the relation between the players' beliefs and risk attitudes, we found that nearly 75 percent of the decisions were consistent, meaning that the players chose the best response to their stated beliefs given the elicited risk attitudes.

In economic theory, it is postulated that varying the degree of information provided to subjects affects their behavior. To test our third hypothesis, we analyzed the decisions of the players in the two different treatments. As shown in Tables 4 and 5, the majority of players chose the risky payoff, Alternative B in both treatments. In Table 9, we present the numbers of choices in both alternatives for all 72 players (again, the one "indifferent" decision was not reported) in both treatments. 


\begin{tabular}{|l|c|c|}
\hline \multirow{2}{*}{ Corruption Game } & \multicolumn{2}{|c|}{ No. of choices of: } \\
\cline { 2 - 3 } & Alternative A & Alternative B \\
\hline Modified Corruption Game & 68 & 292 \\
\hline
\end{tabular}

Table 9: No. of choices of Alternatives A and B in both games

The differences become more obvious when one considers the averages. As Figure 1 shows, the variation in the degree of uncertainty achieved by providing less information about the probabilities of obtaining the higher payoff in the Modified Corruption Game significantly reduced the fraction of players choosing Alternative B (chi-square test, $1 \%$ level). Thus, we are also compelled to reject our third hypothesis.

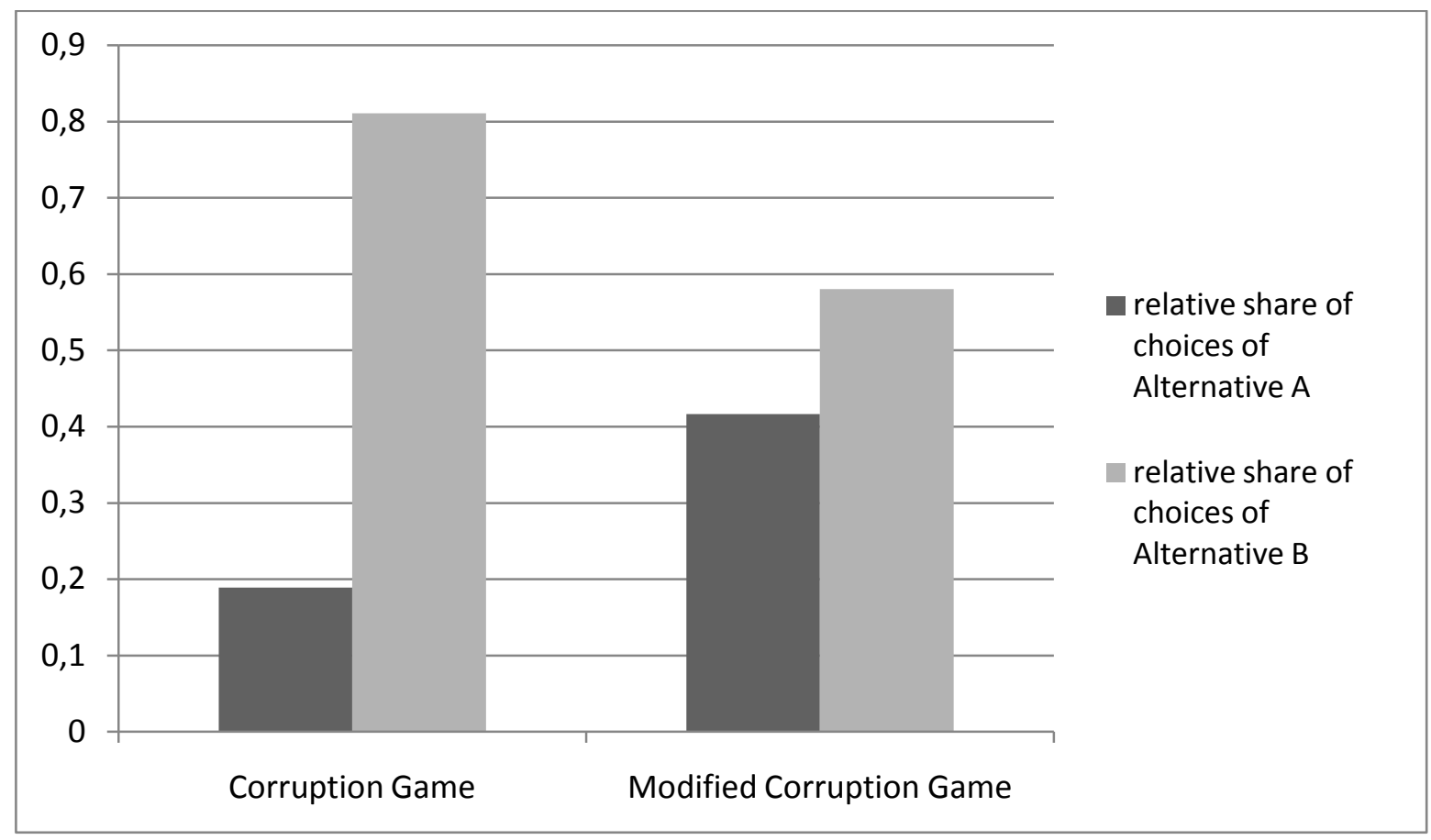

Figure 1: Relative shares of choices of Alternatives $A$ and $B$ in both treatments

\section{Conclusion}

This study was motivated by of the desire to investigate the effect of different degrees of uncertainty on players' decisions in an environment of corruption. At the same time, we also wanted to find out whether the players' risk attitudes or beliefs determined their decisions in a game.

Using the common definition of the two kinds of uncertainty, we were able to compare our players' decisions in risky situations with their decisions in situations with different degrees of uncertainty. We designed the decision problem as a coordination game, where the "corrupt outcome" was modeled as a binary lottery representing various assumptions (such as e.g. being caught or having one's bribes refused). In addition, we elicited the players' risk attitudes and beliefs.

Using lottery choices to identify the players' risk attitudes, we found that the average player was risk averse and used a threshold strategy. In relating the players' risk attitudes to their decisions in the game, we did not find evidence of a determining influence. In contrast, the elicited beliefs seem to be a much better predictor for the players' behavior. Moreover, the behavior of the majority of the 
participants in our study was consistent with respect to their stated beliefs and risk attitudes. In the context of corruption, the players built subjective probabilities about the odds of concealing their corrupt behavior, a practice which is necessary for successfully engaging in corrupt acts.

The comparison between the treatments with different degrees of uncertainty lends support to the hypothesis that increasing uncertainty reduces corruption. In other words, to effectively fight against corruption, an agency should publicize convictions, but should not provide any information about the frequency of uncovering corrupt activities. This is in line with the work of Cadot (1987), whose theoretical results show that information affects corruption.

\section{References}

Abbink, K., Henning-Schmidt, H., 2006. Neutral versus loaded instructions in a bribery experiment. Experimental Economics 9, 103-121.

Andvig, J. C., Moene, K. O., 1990. How corruption may corrupt. Journal of Economic Behavior \& Organization 13, 63-76.

Brunetti, A., Weder, B., 2003. A free press is bad news for corruption. Journal of Public Economics 87, 1801-1824.

Cadot, O., 1987. Corruption as a gamble. Journal of Public Economics 33, 223-244.

Costa-Gomes, M. A., Weizsäcker, G., 2008. Stated Beliefs and Play in Normal-Form Games. Review of Economic Studies 75, 729-762.

Fischbacher, U., 2007. z-Tree: Zurich toolbox for ready-made economic experiments. Experimental Economics 10, 171-178.

Gerber, A., Learning in and about Games. Working Paper Series. Institute for Empirical Research in Economics, University of Zurich, Zurich, 2006.

Goeree, J. K., et al., 2003. Risk averse behavior in generalized matching pennies games. Games and Economic Behavior 45, 97-113.

Greiner, B. The Online Recruitment System ORSEE 2.0 - A Guide for the Organization of Experiments in Economics. Working Paper Series of Economics. University of Cologne, Cologne, 2004.

Groenendijk, N., 1997. A principal-agent model of corruption. Crime, Law \& Social Change 27, 207-229.

Harsanyi, J. C., Selten, R., 1988. A General Theory of Equilibrium Selection in Games. MIT Press, Cambridge.

Heinemann, F., et al., 2004. The Theory of Global Games on Test: Experimental Analysis of Coordination Games with Public and Private Information. Econometrica 72, 1583-1599.

Heinemann, F., et al., 2009. Measuring Strategic Uncertainty in Coordination Games. The Review of Economic Studies 76, 181-221.

Holt, C. A., Laury, S. K., 2002. Risk Aversion and Incentive Effects. The American Economic Review 92, 1644-1655.

Knight, F. H., 1921. Risk, Uncertainty and Profit. Hart, Schaffner \& Marx; Boston: Houghton Mifflin Company, The Riverside Press, Cambridge. 
Lippman, S. A., et al. Chapter 6 The economics of uncertainty: Selected topics and probabilistic methods. Handbook of Mathematical Economics Elsevier, 1981, pp. 211-284.

Lui, F. T., 1986. A dynamic model of corruption deterrence. Journal of Public Economics 31, 215-236.

Neumann, T., Vogt, B. Do Players' Beliefs or Risk Attitudes Determine The Equilibrium Selections in 2×2 Coordination Games?. FEMM Working Paper Series, No. 09024. University of Magdeburg, Magdeburg, 2009.

Nyarko, Y., Schotter, A., 2002. An Experimental Study of Belief Learning using Elicited Beliefs. Econometrica 70, 971-1005.

Palfrey, T. R., Wang, S. W., 2009. On eliciting beliefs in strategic games. Journal of Economic Behavior \& Organization 71, 98-109.

Reinikka, R., Svensson, J. The Power of Information: Evidence from a Newspaper Campaign to Reduce Capture. World Bank Policy Research Working Paper No. 3239. The World Bank, 2004.

Rose-Ackerman, S., 1975. The economics of corruption. Journal of Public Economics 4, 187-203.

Schmidt, D., et al., 2003. Playing safe in coordination games: the role of risk dominance, payoff dominance, and history of play. Games and Economic Behavior 42, 281-299.

Selten, R., 1998. Axiomatic Characterization of the Quadratic Scoring Rule. Experimental Economics $1,43-62$.

Shleifer, A., Vishny, R. W., 1993. Corruption. The Quarterly Journal of Economics 108, 599-617.

Sonnemans, J., Offerman, T. Is the Quadratic Scoring Rule really incentive compatible?, Working Paper CREED. University of Amsterdam, Amsterdam, 2001.

Straub, P. G., 1995. Risk Dominance and Coordination Failures in Static Games. The Quarterly Review of Economics and Finance 55, 339-363.

Tirole, J., 1996. A Theory of Collective Reputations (with Applications to the Persistence of Corruption and to Firm Quality). The Review of Economic Studies 63, 1-22. 


\section{Appendix}

\section{A Tables}

A.1 Table: Chosen alternative - Lottery choices in the Baseline Treatment

\begin{tabular}{|c|c|c|c|c|c|c|}
\hline \multicolumn{6}{|c|}{ Chosen Alternative (Lottery Choices, Baseline Treatment) - No. of players } \\
\hline No. & Alternative A & \multicolumn{2}{|c|}{ Alternative B } \\
{$[0,(1-w) ; 1,000, w]$} & $\begin{array}{c}\text { No. of players } \\
\text { who chose A }\end{array}$ & $\begin{array}{c}\text { No. of players } \\
\text { who chose B }\end{array}$ & $\begin{array}{c}\text { No. of } \\
\text { indifferent } \\
\text { players }\end{array}$ \\
\hline 1 & 600 Points & .99 & .01 & $\mathbf{3 3}$ & 3 & 0 \\
\hline 2 & 600 Points & .95 & .05 & $\mathbf{3 3}$ & 3 & 0 \\
\hline 3 & 600 Points & .90 & .10 & $\mathbf{3 3}$ & 3 & 0 \\
\hline 4 & 600 Points & .80 & .20 & $\mathbf{3 4}$ & 1 & 1 \\
\hline 5 & 600 Points & .70 & .30 & $\mathbf{3 4}$ & 0 & 2 \\
\hline 6 & 600 Points & .60 & .40 & $\mathbf{3 4}$ & 2 & 0 \\
\hline 7 & 600 Points & .50 & .50 & $\mathbf{2 8}$ & 5 & 3 \\
\hline 8 & 600 Points & .40 & .60 & $\mathbf{2 3}$ & $\mathbf{4}$ & $\mathbf{9}$ \\
\hline 9 & 600 Points & .30 & .70 & $\mathbf{1 2}$ & $\mathbf{2 0}$ & $\mathbf{4}$ \\
\hline 10 & 600 Points & .20 & .80 & 5 & $\mathbf{2 7}$ & 4 \\
\hline 11 & 600 Points & .10 & .90 & 1 & $\mathbf{3 5}$ & 0 \\
\hline 12 & 600 Points & .05 & .95 & 1 & $\mathbf{3 5}$ & 0 \\
\hline 13 & 600 Points & .01 & .99 & 0 & $\mathbf{3 6}$ & 0 \\
\hline
\end{tabular}

\section{A.2 Table: Chosen alternative - Lottery choices in the Uncertain Treatment}

\begin{tabular}{|c|c|c|c|c|c|c|}
\hline \multicolumn{6}{|c|}{ Chosen Alternative (Lottery Choices, Uncertain Treatment) - No. of players } \\
\hline No. & Alternative A & \multicolumn{2}{|c|}{$\begin{array}{c}\text { Alternative B } \\
{[0,(1-w) ; 1,000, w]}\end{array}$} & $\begin{array}{c}\text { No. of players } \\
\text { who chose A }\end{array}$ & $\begin{array}{c}\text { No. of players } \\
\text { who chose B }\end{array}$ & $\begin{array}{c}\text { No. of } \\
\text { indifferent } \\
\text { players }\end{array}$ \\
\hline 1 & 600 Points & .99 & .01 & $\mathbf{3 0}$ & 2 & 4 \\
\hline 2 & 600 Points & .95 & .05 & $\mathbf{3 4}$ & 0 & 2 \\
\hline 3 & 600 Points & .90 & .10 & $\mathbf{3 5}$ & 0 & 1 \\
\hline 4 & 600 Points & .80 & .20 & $\mathbf{3 6}$ & 0 & 0 \\
\hline 5 & 600 Points & .70 & .30 & $\mathbf{3 4}$ & 2 & 0 \\
\hline 6 & 600 Points & .60 & .40 & $\mathbf{3 4}$ & 2 & 0 \\
\hline 7 & 600 Points & .50 & .50 & $\mathbf{2 4}$ & 7 & 5 \\
\hline 8 & 600 Points & .40 & .60 & $\mathbf{1 9}$ & $\mathbf{8}$ & $\mathbf{9}$ \\
\hline 9 & 600 Points & .30 & .70 & 6 & $\mathbf{2 2}$ & 8 \\
\hline 10 & 600 Points & .20 & .80 & 4 & $\mathbf{2 8}$ & 4 \\
\hline 11 & 600 Points & .10 & .90 & 2 & $\mathbf{3 3}$ & 1 \\
\hline 12 & 600 Points & .05 & .95 & 0 & $\mathbf{3 5}$ & 1 \\
\hline 13 & 600 Points & .01 & .99 & 0 & $\mathbf{3 6}$ & 0 \\
\hline
\end{tabular}


A.3 Table: Switching points of the 8 players who did not play a threshold strategy

\begin{tabular}{|c|c|c|c|c|c|c|c|c|c|c|c|c|c|}
\hline \multirow{2}{*}{ Player } & \multicolumn{13}{|c|}{ No. of decision pairs in the lottery choices } \\
\hline & 1 & 2 & 3 & 4 & 5 & 6 & 7 & 8 & 9 & 10 & 11 & 12 & 13 \\
\hline 1 & A & B & B & A & A & A & A & A & ind. & ind. & B & B & B \\
\hline 2 & $A$ & $A$ & $A$ & $A$ & $A$ & $A$ & $B$ & $A$ & $B$ & $B$ & $B$ & $B$ & $B$ \\
\hline 3 & $B$ & $B$ & $B$ & ind. & ind. & $A$ & ind. & ind. & $A$ & $B$ & $B$ & $B$ & $B$ \\
\hline 4 & $B$ & B & B & $B$ & ind. & $A$ & $A$ & $A$ & ind. & $B$ & B & B & $B$ \\
\hline 5 & $A$ & $A$ & $A$ & $A$ & $A$ & $B$ & $A$ & $A$ & $B$ & $B$ & $B$ & $B$ & $B$ \\
\hline 6 & $A$ & $A$ & $A$ & $A$ & $A$ & $A$ & B & $A$ & $B$ & $A$ & $B$ & $A$ & $B$ \\
\hline 7 & A & $A$ & ind. & A & B & B & $A$ & $B$ & $B$ & A & A & B & B \\
\hline 8 & A & A & A & A & $\mathrm{B}$ & B & $B$ & $A$ & B & $B$ & $B$ & B & B \\
\hline
\end{tabular}

Table 10: $A$ = Alternative $A, B$ = Alternative $B$, and ind. = indifferent 


\section{B Written Instructions (Translations)}

\section{B.1 Baseline Treatment (Lottery choices and Corruption Game)}

\section{Welcome to the MaXLab!}

\section{Instructions}

You are about to take part in an experiment that investigates behavior in uncertain situations. The experiment consists of two parts.

In the first part you will be asked to decide between a sure payoff (Alternative A) and a lottery (Alternative B). For each decision scenario, the payoffs and probabilities are as follows:

\begin{tabular}{r|c|c|c|c|c|c}
\hline \hline & Alternative A & \multicolumn{2}{|c|}{ Alternative B } & \multicolumn{3}{|c}{ Your decision } \\
\hline $\begin{array}{r}\text { Payoff in } \\
\text { points }\end{array}$ & 600 & 1,000 & 0 & & & \\
$\begin{array}{r}\text { Probability } \\
100 \% \text { (sure) }\end{array}$ & $90 \%$ & $10 \%$ & & & \\
\hline
\end{tabular}

In the above example, if you choose Alternative $A$, you will receive a sure payoff of 600 points. If you choose Alternative $B$, you have a $90 \%$ probability of winning 1,000 points and a $10 \%$ probability of winning 0 points.

Generally, your decisions are as follows:

\begin{tabular}{r|c|c|c|c|c|c}
\hline \hline & Alternative A & \multicolumn{2}{|c|}{ Alternative B } & \multicolumn{3}{|c}{ Your decision } \\
& 600 & $\mathrm{G}_{1}$ & $\mathrm{G}_{2}$ & & & \\
\hline $\begin{array}{r}\text { Payoff in } \\
\text { points }\end{array}$ & $w$ & $100-w$ & & & \\
$\begin{array}{r}\text { Probability } \\
100 \% \text { (sure) }\end{array}$ & $w$ & & & \\
\hline \hline
\end{tabular}

If you choose the lottery, it will be played by drawing a ball from a bingo cage containing a specified number of red and blue balls, reflecting the probabilities shown above (the number of red balls corresponds to the probability of payoff one (G1) and the number of blue balls corresponds to the probability of payoff two (G2)).

Your decisions will be realized at the very end of the experiment.

For every 15 points you accrue during the experiment, you will receive 1 euro cent. 


\section{Part 1 (Lottery choices - elicitation of risk attitudes)}

For each of the following 13 queries, please choose either Alternative $A$ or Alternative B; if you have no preference, click the middle box ("I am indifferent between these two alternatives").

As an example, the screenshot below shows the design of the decisions:

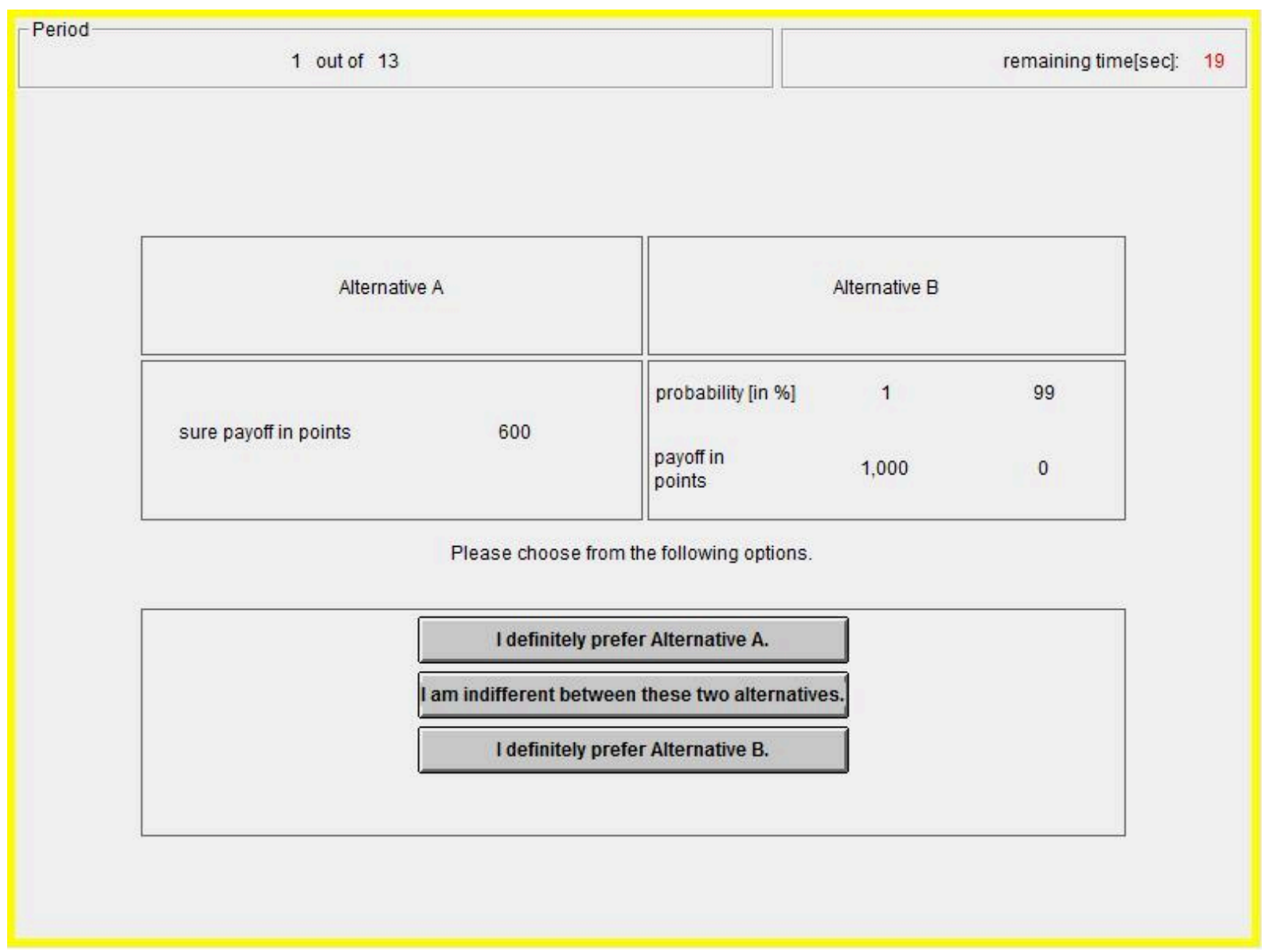

At the end of the entire experiment, one of your 13 decisions will be realized according to a random drawing from a bingo cage containing 13 balls numbered from 1 to 13 . If you chose Alternative $A$ in this decision, you will obtain the sure payoff of 600 points. If you chose Alternative $B$, the lottery will be played by drawing a ball from a bingo cage containing $(w)$ red and $(100-w)$ blue balls. If a red ball is drawn, you will receive 1,000 points; if a blue ball is drawn, you will receive 0 points. In the case of indifference, a coin toss determines which alternative will be realized (tails = Alternative $A$, heads = Alternative B). 


\section{Part II (Corruption Game)}

You are in a group with five other participants. In each case, you will be asked to decide between two alternatives: Alternative A provides a sure payoff of 600 points, while Alternative B provides a payoff of 1,000 points with probability $[w(m)]$ and 0 points with probability $[100-w(m)]$. The probabilities depend on the number of players choosing Alternative $B$.

\section{Your decision:}

Alternative A: 600 points (sure payoff)

Alternative B: $\quad 1,000$ points with probability $\mathrm{w}(\mathrm{m})$

0 points with probability $100-\mathrm{w}(\mathrm{m})$

The table below displays the resulting probabilities for Alternative $B$ according to the percentage of players choosing Alternative $B$.

\begin{tabular}{ccc}
\hline $\begin{array}{c}\text { Number of players choosing } \\
\text { Alternative B }\end{array}$ & $\begin{array}{c}\text { Probability } \\
\boldsymbol{w}(\boldsymbol{m})\end{array}$ & $\begin{array}{c}\text { Probability } \\
\mathbf{1 0 0}-\boldsymbol{w}(\boldsymbol{m})\end{array}$ \\
\hline $\mathbf{1}$ & $50 \%$ & $50 \%$ \\
$\mathbf{2}$ & $60 \%$ & $40 \%$ \\
$\mathbf{3}$ & $70 \%$ & $30 \%$ \\
$\mathbf{5}$ & $80 \%$ & $20 \%$ \\
$\mathbf{6}$ & $90 \%$ & $10 \%$ \\
\hline \hline
\end{tabular}

Please use the computer to indicate which alternative you prefer. If you are indifferent between the two alternatives, please check the box labeled "indifferent".

\begin{tabular}{|l|l|l|l|}
\hline Your decision: & Alternative $A$ & Alternative $B$ & Indifferent \\
\cline { 2 - 4 } & & & \\
\hline
\end{tabular}

In the case of indifference, one alternative will be randomly selected, with a probability of 50 percent for each alternative. This random result will be shown to you.

After all participants have made their decisions, those who chose Alternative A will obtain a payoff of 600 points. For the remaining participants, depending on the number of participants who chose Alternative $B$, the corresponding payoff will be awarded. After each round, all participants are informed of how many players received 0 points in the last round played.

This part is played 10 times, and you can choose between Alternative A, Alternative B, or indifference between the two in each round. 


\section{B.2 Uncertain Treatment (Lottery choices and Modified Corruption Game)}

Welcome to the MaXLab!

\section{Instructions}

You are about to take part in an experiment that investigates behavior in uncertain situations. The experiment consists of two parts.

In the first part you will be asked to decide between a sure payoff (Alternative A) and a lottery (Alternative B). For each decision scenario, the payoffs and probabilities are as follows:

\begin{tabular}{r|c|c|c|c|c|c}
\hline \hline & Alternative A & \multicolumn{2}{|c|}{ Alternative B } & \multicolumn{3}{c}{ Your decision } \\
& 600 & 1,000 & 0 & & & \\
$\begin{array}{r}\text { Payoff in } \\
\text { points }\end{array}$ & $100 \%$ (sure) & $90 \%$ & $10 \%$ & & & \\
Probability & $10 \%$ & & & & \\
\hline \hline
\end{tabular}

In the above example, if you choose Alternative $A$, you will receive a sure payoff of 600 points. If you choose Alternative $B$, you have a $90 \%$ probability of winning 1,000 points and a $10 \%$ probability of winning 0 points.

In this example: If you prefer Alternative $A$, you receive a sure payoff of 600 points. If you prefer Alternative $B$, you win 1,000 points with probability $90 \%$ and 0 points with probability $10 \%$.

Generally, your decisions are as follows:

\begin{tabular}{r|c|c|c|c|c|c}
\hline \hline & Alternative A & \multicolumn{3}{|c|}{ Alternative B } & \multicolumn{4}{|c}{ Your decision } \\
& 600 & $\mathrm{G}_{1}$ & $\mathrm{G}_{2}$ & & & \\
\hline $\begin{array}{r}\text { Payoff in } \\
\text { points }\end{array}$ & $w$ & $100-w$ & & & \\
$\begin{array}{r}\text { Probability } \\
100 \% \text { (sure) }\end{array}$ & $w$ & & & & \\
\hline
\end{tabular}

If you choose the lottery, it will be played by drawing a ball from a bingo cage containing a specified number of red and blue balls, reflecting the probabilities shown above (the number of red balls corresponds to the probability of payoff one (G1) and the number of blue balls corresponds to the probability of payoff two (G2)).

Your decisions will be realized at the very end of the experiment.

For every 15 points you accrue during the experiment, you will receive 1 euro cent. 


\section{Part I (Lottery choices - elicitation of risk attitudes)}

For each of the following 13 queries, please choose either Alternative A or Alternative B; if you have no preference, click the middle box ("I am indifferent between these two alternatives").

As an example, the screenshot below shows the design of the decisions:

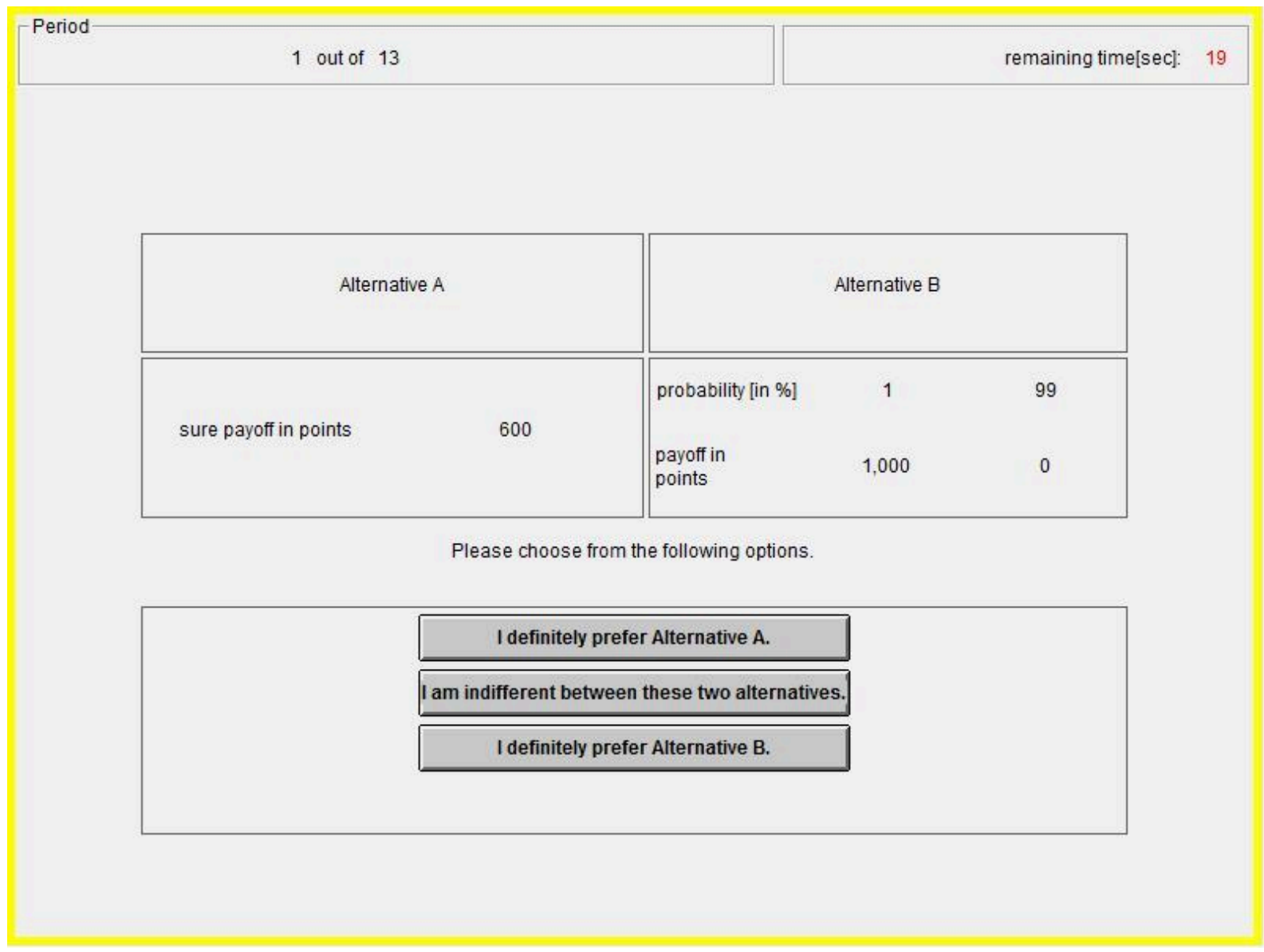

At the end of the entire experiment, one of your 13 decisions will be realized according to a random drawing from a bingo cage containing 13 balls numbered from 1 to 13. If you chose Alternative $A$ in this decision, you will obtain the sure payoff of 600 points. If you chose Alternative $B$, the lottery will be played by drawing a ball from a bingo cage containing $(w)$ red and $(100-w)$ blue balls. If a red ball is drawn, you will receive 1,000 points; if a blue ball is drawn, you will receive 0 points. In the case of indifference, a coin toss determines which alternative will be realized (tails = Alternative $A$, heads = Alternative B). 


\section{Part II (Modified Corruption Game - direct belief elicitation)}

You are in a group with five other participants. You will be asked to decide between two alternatives: Alternative A provides a sure payoff of 600 points, while Alternative B provides a payoff of 1,000 points with probability $w(m)$ and 0 points with probability $100-w(m)$. The probabilities are unknown to all participants.

The probabilities depend on the number of players in your group choosing Alternative $B$. The more players who choose Alternative $B$, the higher the probability $w(m)$ (the probability of getting 1,000 points) will be.

Your decision:

Alternative A: 600 points (sure payoff)

Alternative B: $\quad 1,000$ points with probability $\boldsymbol{w}(\boldsymbol{m})$

0 points with probability $100-\boldsymbol{w}(\boldsymbol{m})$

Please use the computer to indicate which alternative you prefer. If you are indifferent between both alternatives, please check the box labeled "indifferent".

\begin{tabular}{|l|l|l|l|}
\hline Your decision: & Alternative A & Alternative B & Indifferent \\
\cline { 2 - 4 } & & & \\
\hline
\end{tabular}

In the case of indifference, one alternative will be randomly selected, with a probability of 50 percent for each alternative. This random result will be shown to you.

In addition, you will be asked to estimate the probability of Alternative B providing 1,000 points.

Please indicate your estimate with a number between 0 (Alternative $B$ will definitely provide 0 points) and 100 (Alternative $B$ will definitely provide 1,000 points).

For this estimate you will be rewarded according to the following function:

$$
E=150 \cdot\left[1-\left(w(m)-\frac{b}{100}\right)^{2}\right] \text {, with } \mathrm{w}(\mathrm{m})=\text { real probability of obtaining } 1,000 \text { points. }
$$


The table below shows some randomly selected combinations of $w(m)$ and the resulting payoffs $(b)$.

\begin{tabular}{|c|c|c|c|c|c|c|c|c|c|c|c|c|}
\hline & \multicolumn{11}{|c|}{ Real probability $w(m)$} \\
\hline & & 0 & 10 & 20 & 30 & 40 & 50 & 60 & 70 & 80 & 90 & 100 \\
\hline \multirow{11}{*}{ 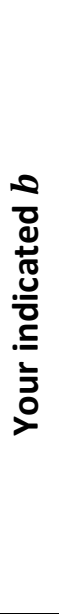 } & 0 & 150 & 148.5 & 144 & 136.5 & 126 & 112.5 & 96 & 76.5 & 54 & 28.5 & 0 \\
\hline & 10 & 148.5 & 150 & 148.5 & 144 & 136.5 & 126 & 112.5 & 96 & 76.5 & 54 & 28.5 \\
\hline & 20 & 144 & 148.5 & 150 & 148.5 & 144 & 136.5 & 126 & 112.5 & 96 & 76.5 & 54 \\
\hline & 30 & 136.5 & 144 & 148.5 & 150 & 148.5 & 144 & 136.5 & 126 & 112.5 & 96 & 76.5 \\
\hline & 40 & 126 & 136.5 & 144 & 148.5 & 150 & 148.5 & 144 & 136.5 & 126 & 112.5 & 96 \\
\hline & 50 & 112.5 & 126 & 136.5 & 144 & 148.5 & 150 & 148.5 & 144 & 136.5 & 126 & 112.5 \\
\hline & 60 & 96 & 112.5 & 126 & 136.5 & 144 & 148.5 & 150 & 148.5 & 144 & 136.5 & 126 \\
\hline & 70 & 76.5 & 96 & 112.5 & 126 & 136.5 & 144 & 148.5 & 150 & 148.5 & 144 & 136.5 \\
\hline & 80 & 54 & 76.5 & 96 & 112.5 & 126 & 136.5 & 144 & 148.5 & 150 & 148.5 & 144 \\
\hline & 90 & 28.5 & 54 & 76.5 & 96 & 112.5 & 126 & 136.5 & 144 & 148.5 & 150 & 148.5 \\
\hline & 100 & 0 & 28.5 & 54 & 76.5 & 96 & 112.5 & 126 & 136.5 & 144 & 148.5 & 150 \\
\hline
\end{tabular}

After all participants have made their decisions, those who chose Alternative A will obtain a payoff of 600 points. For the remaining participants, depending on the number of participants who chose Alternative B, the corresponding payoff will be awarded. After each round, all participants are informed of how many players received 0 points in the last round played.

This part is played 10 times, and you can choose between Alternative A, Alternative B, or indifference between the two in each round.

Thanks for participating in our experiment! 


\section{Working Paper Series in Economics}

recent issues

No. 6 Siegfried Berninghaus, Sven Haller, Tyll Krüger, Thomas Neumann, Stephan Schosser, Bodo Vogt: Risk attitude, beliefs, and information in a corruption game An experimental analysis, September 2010

No. 5 Ingrid Ott, Susanne Soretz: On the role of productive government spendings for convergence of a growing economy with heterogenous specialists, August 2010

No. 4 Anna Chernobai, Christian Menn, Svetlozar T. Rachev, Stefan Trück: Estimation of operational value-at-risk in the presence of minimum collection threshold: An empirical study, August 2010

No. 3 Omid Rezania, Svetlozar T. Rachev, Edward Sun, Frank J. Fabozzi: Analysis of the intraday effects of economic releases on the currency market, August 2010

No. 2 Young Shin Kim, Svetlozar T. Rachev, Michele Leonardo Bianchi, Ivan Mitov, Frank J. Fabozzi: Time series analysis for financial market meltdowns, August 2010

No. 1 Biliana Güner, Svetlozar T. Rachev, Daniel Edelman, Frank J. Fabozzi: Bayesian inference for hedge funds with stable distribution of returns, August 2010 